Portland State University

PDXScholar

1977

\title{
An evaluation system for alcohol and drug programs
}

Michael J. Schrunk

Portland State University

Follow this and additional works at: https://pdxscholar.library.pdx.edu/open_access_etds

Part of the Social Work Commons

Let us know how access to this document benefits you.

\section{Recommended Citation}

Schrunk, Michael J., "An evaluation system for alcohol and drug programs" (1977). Dissertations and Theses. Paper 2160.

https://doi.org/10.15760/etd.2158

This Thesis is brought to you for free and open access. It has been accepted for inclusion in Dissertations and Theses by an authorized administrator of PDXScholar. Please contact us if we can make this document more accessible: pdxscholar@pdx.edu. 
AN EVALUATION SYSTEM FOR

ALCOHOL AND DRUG PROGRAMS

by

MICHAEL J. SCHRUNK

A practicum submitted in partial fulfillment of the requirements for the degree of

MASTER OF SOCIAL WORK

Portland State University

School of Social Work

1977 
TABLE OF CONTENTS

PAGE

PREFACE . . . . . . . . . . . . . . . . . . . . . .

CHAPTER

I THE SYSTEM TO BE EVALUATED . . . . . . . . . . . . . . 1

Emergency Care of Detoxification Facilities . . . . 1

Residential Care Facilities . . . . . . . . . 3

Inpatient Care . . . . . . . . . . . . . 4

Outpatient Care... . . . . . . . . . . 6

Partial Day/Night Care . . . . . . . . . . . 7

il THE EVALUATION OF COMPETENT IDENTIFICATION OF CLIENTS . . 9

Definition of Substance Problems and Problems

in Assessing Their Existence . . . . . . . . . . 9

Present Guidelines for the Assessment of Client

Problems . . . . . . . . . . . . . . . . .

Establishment of a Range of Considerations to be made in Assessing Substance Abuse Problems . . . .

Substance Use by Frequency and Amount

Results of Substance Use

Precursors or Correlates of Substance Use Problems

Client Strengths and Resources

Organization of Client Assessment Information in a

Format Useful to the Program (or Other Decision

Makers) . . . . . . . . . . . . . . . . 21

II GOALS OF TREATMENT . . . . . . . . . . . . . . . 23

IV ASSESSMENT OF THE RESOURCES APPLIED TO ATTAIN GOALS . . . 28

V ASSESSMENT OF THE OUTCOME OF TREATMENT . . . . . . . . . 31 
Readmission Rates . . . . . . . . . . . . . 33

Recidivism Rates . . . . . . . . . . . . 34

Goal Attainment Scaling . . . . . . . . . . . 35

Life Activities Inventory . . . . . . . . . . . . 37

Personal Adjustment and Role Skills (PARS) . . . . . 38

Denver Community Mental Health Questionnaire (DCMHQ) 38

Community Adaptation Schedule (CAS) . . . . . . . . 39

Global Assessment Scale . . . . . . . . . . . 40

VI CONSIDERATIONS REGARDING THE IMPLEMENTATION OF AN

EVALUATION SYSTEM . . . . . . . . . . . . . . . 42

REFERENCES CITED . • . . . . . . . . . . . . . . . . . 48 


\section{PREFACE}

This paper was written as a practicum project for the Portland State University School of Social Work. It attempts to deal with the Program Office needs for an evaluation system.

The Office of Programs for Alcohol and Drug Problems is the designated "Single State Authority" for the planning and development of alcohol and drug programs. It is within the State Mental Health Division, and is the interface between the Division, the counties, and the federal government with regard to alcohol and drug programs. The Division's office of Management Support Services (MSS) is charged with the responsibility of developing an evaluation system for programs. This is being done in regard to the needs of programs and decision-makers concerned with programs. The Program Office is now providing input to MSS largely through this practicum paper, and through the involvement of the author with staff of MSS and the Division's Task Force on Evaluation Systems. The goal of the practicum, and the involvement with MSS, which will continue, is to assist in the development of an evaluation system that will enable the Program Office to better perform the tasks of assessing programs, and planning for this further development.

While the subject is beyond the scope of this paper, such an evaluation system would be useful to individuals, organizations, and high level decision-makers outside the Program Office. 
For an evaluation system to be of use to the Program office (or the other decision makers involved with alcohol and drug programs), it must provide systematic information regarding the extent to which the alcohol and drug service system and elements within it are able to:

1. Identify the problems of potential clientele;

2. Assign or establish goals which clients may realistically be helped to attain; and

3. Provide treatment or services which enable them to reach their goals.

Beyond answering process oriented questions such as these, the system must develop information concerning the impact, on the lives of clients, and on the community, of the services. It must provide this feedback in a way that is usable to programs so they may alter approaches to client problems, to the Program office, and to the hierarchy of government officials responsible for programs. 


\section{CHAPTER I \\ THE SYSTEM.TO BE EVALUATED}

The evaluation of a program, or of this system of programs, must begin with an understanding of what it is they are supposed to do.

Oregon's alcohol and drug service delivery system is composed of five basic program elements:

1. Emergency care or detoxification services;

2. Residential care;

3. Inpatient care;

4. Outpatient care;

5. Partial day/night care:

Perhaps not surprisingly there is considerable confusion over the functions or missions of these elements. A variety of expectations that range in source from the state legislature to service consumers causes some of this confusion. To comprehend the information needs of the Program Office for the planning, assessment, and influencing of change within programs it is necessary to understand the variety of expectations placed on each element.

EMERGENCY GARE OR DETOXIFICATION FACILITIES

A detoxification center is defined in Oregon Revised Statute 430.306, Section $4(40, \mathrm{p} .880)$ as a "...facility...that provides emergency care or treatment for alcoholics or drug dependent persons."

Both Oregon State Mental Health Division Administrative Rule 52.000, 
which promulgates rules for alcohol detoxification centers, and 53.010, which promulgates rules for drug detoxification, stipulate a range of services in addition to the emergency detoxification functions, that include assistance in beginning re-adjustment (39, p. 2; 42, p. 4).

Though compliance with Joint Commission on Accreditation of Hospitals standards for alcohol and drug programs is not a current Mental Health Division requirement for community programs, future rules established by the Division may be comprehensive of some of these standards. The Commission manual for the accreditation of alcohol programs includes in its statement of principles for detoxification centers requirements to provide for "the evaluation of medical, psychological, and social needs leading to the development of plans for continuity of care" (22, p. 35). The Commission's standards for drug abuse treatment and rehabilitation programs pertain principally to emergency care in discussing detoxification facilities, but implies longer term attempts to reduce substance abuse subsequent to detoxification (23, p. 42, 43). Detoxification centers, particularly those for alcohol withdrawal, have other, less clear missions. The Uniform Alcoholism and Intoxication Treatment Act of 1971 (federal) provides that in handling of the public inebriate "a noncriminal, voluntary, treatment oriented approach to the control and care of alcoholics is desirable and required by the states" $(52, p \cdot 1)$.

The mission of the detoxification center, taken from these laws, standards, and guidelines includes:

1. The provision of potentially life saving care or care to diminish the suffering and damage to the individual from the 
effects of intoxification and withdrawal; and

2. The provision of a beginning of long term rehabilitation for the individual to overcome substance abuse problems.

Beyond that, a third expectation comes from law makers and a variety of agencies such as the police. Detoxification centers for alcohol treatment are expected to impact on the entire community by "eliminating the public inebriate from the criminal justice system." The first year evaluation of the David P. Hooper Detoxification Center in Portland, for example, stated that "the primary objective of the center was the removal of the indigent public inebriate from the continuing cycle of arrest and incarceration..." (emphasis contained in text, 35, p. 3).

An evaluation dealing with detoxification center performance would have to assist the Program office in testifying to what extent each of these mandates and implicit goais were met.

\section{RESIDENTIAL CARE FACILITIES}

Standards or regulations for alcohol and drug residential care facilities place two principle expectations on the programs:

1. To provide for the care, defined as room and board in an environment free from alcohol and unauthorized drugs, for persons requiring such care because of the consequences of alcohol and drug abuse (45, Section 8, p. 880;40, p. 1).

2. To provide a long term program for the rehabilitation of the substance abuser utilizing a variety of counseling modes, self-help such as Alcoholics Anonymous and supportive services such as the Vocational Rehabilitation Division, socialization and recreational activities (40, p. 2-3; 
22 , p. 47-50;23, p. 46-61;58, p. 29).

Implicit in all of these standards and rules, since stipulations regarding treatment planning and provision, etc., are contained in each, is the objective that rather than simply caring for clients on a day to day or emergency basis, programs must attempt to render clients independently free of substance abuse problems. The Program office needs evaluative information regarding the accomplishment of both general functions in order to gauge the quality of residential care facilities, and to determine the extent to which they accomplish their mandated missions.

ORS 430.306, which was passed in 1973, provides for the establishment or continuation of "other treatment facilities including outpatient facilities, inpatient facilities, and other such facilities as the Division (Mental Health) determines suitable...for the diagnosis and evaluation, medical care, detoxification, social services or rehabilitation for alcoholics or drug dependent persons..." (45, Section 10, p. 880).

This legislation provides for a range of services beyond emergency or residential care.

\section{INPATIENT CARE}

This service element has the longest history of any in the alcohol and drug treatment system. The service is limited now to the treatment of organic brain syndromes and the psychotic manifestations consequent to severe substance abuse, such as delirium tremons, alcoholic paranoid state, alcoholic deterioration, the acute psychoses with drug intoxication, and Korsacoff's psychosis (13, pp. 25-26, 31). Other functional. disorders such as schizophrenia, paranoid type, may be a presenting admission problem 
at an alcohol and drug inpatient facility since their manifestation is made more florid by the abuse of substances such as alcohol and amphetamines.

The mission or function of these programs is:

1. To provide intensive medically-oriented care to treat the medical or psychiatric sequel to substance abuse; and

2. To reduce the re-occurance of such disorders by rehabilitation to overcome substance dependencies or abuse in the future.

As in the case of residential care facilities, inpatient programs are to provide counseling, social services, and, in addition, psychotrophic medication as indicated, special diets, exercise regimens, and drugs to control or block substance use such as dysulphurim (Antabuse) and methadone.

The requirements or standards followed by inpatient programs are those promulgated by the Joint Commission on Accreditation of Hospitals (22, pp. 41-44; 23, pp. 35-61). Beyond these standards, drug treatment services must comply with National Institute of Drug Abuse standards (58, pp. 27-32), which, in addition to traditional treatment modes, require chemical surveillance such as urinalysis.

In planning for the development or change of inpatient programs, the Program office would benefit from an evaluation system that would provide some indications of:

1. Whether certain of the medical and psychiatric problems attendant to substance abuse could be treated in the less expensive residential care facilities (which are also community-based and therefore closer to clients' homes).

2. The extent to which the inpatient rehabilitation programs, and surveillance in the case of drug programs, reduce readmission or reduce the re-occurrence of symptoms resulting 
from continued abuse of substances.

\section{OUTPATIENT CARE}

This service element will be subject to requirements still under consideration and contained in the as yet unnumbered Administrative Rule draft pertaining to "Basic Mental Health Services." This requires a range of rehabilitation services including psychotherapy, psychotropic medication, disulphuram, methadone, provision of, or referral to, "recreational and prevocational services," self-help organizations such as A.A. and Recovery, Inc., and "medical, educational, employment and legal services" (36, pp. 19-20).

Oregon State Mental Health Division Administrative Rule 53.000, which promulgates rules for the "court-mandated client" pertains to other service elements on occasion but is principally relevant to outpatient care. This stipulates the same rehabilitation services as the Basic Services draft but also stipulates cases wherein use of Antabuse or drug urinalysis is required $(41, \mathrm{pp}, 9-10)$ and contains requirements for use of probationary and court powers, and the Motor Vehicles Division prerogatives to suspend drivers licenses, as well as mandatory follow-up. and aftercare requirements of the client. These "parole and probation" type functions are to carry out ORS 482.477 and Section 138 of Senate Bill 1 (the new Motor Vehicles Code) which pertain to mandated treatment or treatment in lieu of sentencing for DUII and other offenses (49, pp. 152-156; 43, p. 61), and ORS 475.675, which pertains to treatment and surveillance of drug dependent persons as a.term of probation after conviction of a crime (8, p. 127). 
The Program office's need for evaluative information with regard to the various outpatient programs include:

1. The extent to which these outpatient services impact on the substance abuse and related problems of clients.

2. For outpatient programs serving the court-mandated client, it must further indicate the extent to which they reduce the recidivism of offenses such as DUII, and felony and misdemeanor offenses more commonly committed by substance abusers. Beyond pure recidivism rates are questions regarding reduction in the expected highway death and injury rates of DUII offenders and the social benefits derived from reduction in instances of other criminal or offensive behavior.

Detoxification centers, residential care facilities, and inpatient facilities might be summarized as having two basic and separable missions; the first, as described above, might be conceived as the maintenance care of substance abusers, consisting of medical services, room, board, etc. The second is rehabilitation services to effect long term change within the individual in regard to substance use and ancilliary problems.

Outpatient services, which are designed for the client living independently in the community, are provided solely to assist the client in changing with regard to substance abuse and related problems, and do not typically involve the level of maintenance care provided in other elements.

PARTIAL DAY/NIGHT CARE

This service component may be conceived in part as a maintenance 
effort which augments or is in lieu of outpatient care. As defined in Oregon State Mental Health Division Administrative Rule 22.000, it also serves as an alternative to state hospitalization for those clients requiring less than 24 -hour-per-day care. Though not specifically. geared to evoking substantive changes in client lifestyle as is generally the goal in outpatient care, these programs do utilize "psychotheraputic and rehabilitative techniques." These are to "reduce emotional distress, improve social and economic functioning, and the ability to cope with the social environment" (38, pp. 2-3).

Evaluation information is necessary to enable assessments of the extent to which each of these elements apply services to their appropriate clients, and accomplish their various missions. 
CHAPTER II

THE EVALUATION OF COMPETENT

IDENTIFICATION OF CLIENTS

For programs to have any meaning, they must first apply services to the proper people. The Program office is therefore concerned that programs assess whether prospective clients have problems or needs which require intervention.

\author{
DEFINITION OF SUBSTANCE PROBLEMS \\ AND PROBLEMS IN ASSESSING THEIR EXISTENCE
}

Programs must have some set of criteria for what constitutes a

problem. To an extent these are now formalized in state statute

ORS 430.306, which defines an "alcoholic" as:

...any person who has lost the ability to control the use of alcoholic beverages or who uses alcoholic beverages to the extent that his health or that of others is substantially impaired or endangered or his social or economic function is substantially disrupted... (45, Section 2, p. 880).

ORS 430.405 defines "drug dependent person" as:

... one who has lost the ability to control the use of dangerous drugs or other drugs with abuse potential or who uses drugs to the extent that his health and that of others is substantially impaired or endangered or his social or economic function is substantially disrupted (47, Section 1, p. 882).

Both statutes recognize "alcoholics" and "drug dependent persons" as

those either physically dependent or psychologically dependent.

The accurate identification of persons experiencing such problems begins with the application of knowledge about substance abuse problems in general to a particular case or instance. To fulfill its mission of 
insuring high quality on the part of alcohol and drug programs, and the application of services to the appropriate clients, the Program Office must be able to ascertain the extent to which this application of knowledge and theory about substance abuse takes place in the decision process regarding whether or not a client requires services.

The decision to include a client in a program after he or she has made the statement "I am an alcoholic", or "I am a drug addict" is a relatively easy one to make. Clinical experience indicates that as one moves away from emergency services, however, such statements become less and less frequent at the point of intake. The search for a quick method of discriminating persons with substance abuse problems from those engaging in the nonproblematic use of alcohol and drugs has been the subject of considerable research and controversy for many years. There is considerable disagreement over what factors can enable such a discrimination.

The National Council on Alcoholism, Inc., has recently released a new definition of alcoholism:

Alcoholism is a chronic, progressive, and potentially fatal disease. It is characterized by tolerance, and physical dependency, pathologic organ changes, or both, all of which are the direct or indirect consequences of the alcohol ingested (54, p. 1).

In the literature supplied with the new definition, Dr. Seixas of the Council adds: .

This definition may lead to significant progress in the treatment of alcoholism and in the evaluation of success of that treatment by separating individuals with single non-recurring problems due to the unusual pharmacological action of alcohol from those whose dependence on alcohol has changed the reaction of their brain to the drug... (54, pp. 1 and 3 ).

Other alcoholigists take less of a "black and white" position on 
what constitutes a need for alcohol treatment. Parker G. Martin uses Don Cahallan's indexes of "alcohol related problems" (cited later) in making estimations of the need for alcohol treatment services across populations. He believes that any person who can be categorized with regard to the Cahallan list is a perspective client, and says "what worthwhile program would turn away a person who has problems with his family, a friend, or neighbors because of alcohol abuse, but who failed to meet some formal criterion for 'alcoholism" (30, p. 8)

Cahallan himself disputes the idea that "one can estimate the frequency of all alcoholism problems from a knowledge of clinical cases of liver cirrhosis or even per capita consumption." He believes it's quite common for people to have a serious drinking problem but that "turnover in these problems is not unusual, with remission of all problems or exchange of one for another over a fairly short time being common" $(10$, p. 6)

The National Institute on Drug Abuse is perplexed with regard to what indicates drug abuse problems as well. No single index has been found to indicate drug abuse problems.

Though Marden, Cahallan and NIDA are talking about assessing substance abuse problems across population, the fact that no one index will point up such a problem applies to individual cases as well. Except at the extremes, a client dying of alcoholic cirrhosis for example, many factors might indicate a substance problem.

While it is difficult to identify an alcohol or drug problem even when a person's substance use is known, it is more difficult in actual clinical practice because of the dynamics and complexities of the problems. Some of the factors which impede quick identification of 
those persons with problems include:

1. Misunderstanding on the part of clients because of simplistic definitions such as that of the National Council on Alcoholism, or mythical pictures of what constitutes an alcohol or drug abuse problem such as those of the skid row alcoholic or the Harlem heroin addict.

2. The fact that clients often don't face problems realistically, but rather react to their concerns, or those of others, over their substance use with denials, rationalizations, and externalizations of the problems caused by their usage onto other causes, etc.

Because of these factors, service workers often make their assessments on basis of considerable inference apart from what their clients say at the point of intake. This problem is compounded by the makeup of the service network and referral system itself. The client referred from court for pre-sentence investigation for posible inclusion in a treatment program following conviction of an offense like DUII or possession of a dangerous drug, may be highly motivated to obtain a negative diagnosis of problems. Family pressures are a frequent instigator of referral and clients may be motivated to obtain a "clean bill of health" to effect peace in the family and prevent treatment from coming between them and desired substances. Because of the inclusion of requirements for treatment planning, etc., in almost all standards developed for programs for alcohol and drug problems, some clients may seek to minimize their substance abuse to avoid treatment, while emphasizing other social or human needs such as that for temporary housing in a residential care facility. 
Unless the service worker entertains a variety of considerations regarding client behavior, and history, these factors can result in a client being incorrectly excluded from treatment. On the other hand, because of fairly extensive, coercive "catchment systems" persons not in need of a particular type of care may be included because of the misjudgement of a service worker regarding the significance of a problem indicator. A DUII offender, for example, referred from court to a treatment program may be included in a wasteful service episode because the worker over-estimates the significance of an offense, or includes the client out of a belief that the referring court expects a treatment plan to be developed as a result of an arrest and conviction, without regard to whether the person actually needs treatment.

PRESENT GUIDELINES FOR THE ASSESSMENT OF CLIENT PROBLEMS

Because of the various influences which may lead to erroneous assessment of a substance abuse problem, the Program office seeks an evaluation system that verifies that programs take factors of diagnostic significance into consideration when deciding whether to admit a client.

The Mental Health Division now mandates, through various Administrative Rules, that information substantiating a client's needs for services be included in treatment records if admitted. This requirement is fairly clear in rules pertaining to detoxification centers (39, p. 3), residential care facilities ( 40 , p. 4), outpatient care for courtmandated clients ( $41, \mathrm{p} .7)$, the drug evaluation and treatment centers (42, p. 4), partial day/night care (38, p. 3), and of course inpatient care through other standards. 
Except for statements such as those in Administrative Rule 53.000, that "the programs help determine whether and the extent to which alcohol and/or drug problems exist based on an assessment of chemical tests" (police blood alcohol tests results for DUII offenders and urinalysis tests for suspected drug abusers), and "emotional, physical, interpersonal, and socio-economic factors in the client's behavior..." (41, p. 7), there are no guidelines for what must be considered in making an assessment.

These various guidelines for client assessment provide little structure for programs. The result is the varied application of divergent points of view regarding what constitutes a problem, across types of programs, and between programs of the same type. One program for example, might evince, in the assessment section of client records, a preoccupation with determining if "addiction", "alpha alcoholism", etc., exists, based on a detailed description of life long substance use patterns. Another program might assess need for treatment based on lengthy descriptions of psychodynamics observed, with relatively little evidence of a consideration of the substance abuse itself.

The Program Office would be supportive of efforts to establish a range of considerations that would stimulate the inclusion of a number of factors or indices of problems in the development of client record data bases for problem assessment. There are a number of factors and considerations which ought to be addressed in the assessment. The specific information sought would vary with the program element. 
A detoxification center for example would have fewer needs for diagnostic information than an outpatient program. Basically, a program that provides longer term, planned treatment needs more diagnostic information to fulfill its mission. While extensive amounts of diagnostic information would be useful to planners, such as from the Program office, some of this information may not be useful to service workers. A rule of thumb ought to be that programs be expected to gather no more information than they are apt to develop treatment plans for. A simple notation by a detoxification center that psychiatric problems exist would be sufficient since it is unlikely to do anything beyond referring the client for that care.

The following represents the types of information which might be obtained from a client undergoing a comprehensive rehabilitation program.

Substance Use by Frequency and Amount

Substance use by frequency and amount, and the source of information regarding these, are significant in determining the existence of problems. With regard to alcohol use, Cahallan makes the observation that:

- It seems only reasonable to expect that problems regarding drinking are not likely to develop unless the individual has first developed a tendency toward fairly often drinking amounts of alcohol sufficient to effect his behavior or his subjective or physical functioning ( $9, \mathrm{p} .22)$.

Frequency of use, and amounts used are important considerations in assessing problems with other drugs as well.

The use of substances other than that being assessed, may be an extremely important area of the inquiry for the worker attempting to make assessment. Follow-up studies in British Columbia of ex-heroin addicts indicated that many of them "merely changed their status from 
that of drug addicts to alcohol addicts" $(6, p .85)$. Studies conducted by the Research Triangle Institute of mixed substance abuse, have led to recommendations that the National Institute on Alcohol Abuse and Alcoholism and the National Institute on Drug Abuse develop training of alcohol and drug counselors with respect to the possible effects and consequences of multiple drug use and behavioral indications of such use.

Because of the unreliability of self-report data regarding use of "other drugs" when a client is being evaluated with regard to one type of substance abuse, the Institute recommended that greater emphasis be placed on validation of report information with spouse, other family members, etc. (59, p. 20). (This necessity for obtaining collateral information from family, etc., is often overlooked in assessing frequency, amounts, and variety of 'substances a client uses. It's importance, however, has been pointed up in many considerations of the validity of client self-report. Ellsworth, for example, found that with mental hospital patients, self-rating with regard to need for hospitalization had no predictive validity, while that of family members was equally valid with staff ratings $(16, p .38)$.)

\section{Results of Substance Use}

Information regarding what happens to a client as a result of substance use is a consideration for the worker in determining if a problem exists. This is perhaps a central consideration in deciding whether a person's use of a substance warrants treatment. If use does not cause or amplify other problems, it is difficult to defend the assessment of that use as a problem. Cahallan used 11 problem factors 
in attempting to distinguish problematic drinking.

1. Frequent intoxication

2. Binge drinking

3. Systematic drinking (loss of control)

4. Psychological dependence

5. Problems with spouse or relatives

6. Problems with friends or neighbors

7. Job problems

8. Problems with the law, police, or accidents

9. Health problems

10. Financial problems

11. Bel1igerence (9, pp. 28-34).

This is the basis for the Marden procedure for estimating the number of problem drinkers in a population and is used by NIAAA. Inquiries regarding similar indices of drug abuse problems which might be applied to assessment indicates that none enjoys wide acceptance at this time (7). However, some of the same factors which apply to the assessment of alcohol problems seemingly might be indicative of problems with other drugs as we11. Frequent intoxication, "binge usage", psychological dependence, problems with spouse, neighbors, jobs, health or the law seem relevant to a consideration of a person's drug use. While belligerence is not as commonly seen among persons intoxicated with substances other than alcohol, the irritability and hostility seen with amphetamine users, ranging to the apathy sometimes seen in association with chronic marijuana use would seem to be indicative of problems resulting from the abuse of these substances. 
Precursors or Correlates of Substance Use Problems

Information regarding the existence of conditions commonly implicated as precursors or correlates of substance use problems, or the manifestations of such problems, might be useful inclusions in the data collection system. These considerations are, of course, very extensive. Some may be derived from client reports, while others would come from collateral contacts such as family members or friends, and others might only be obtained when the service worker has a degree of clinical acumine and knowledge of possible indicators of substance abuse.

In evaluating the quality of client assessments in a program, the Program Office would seek verification that service workers considered factors such as a client's cultural and personal background, modes of handling stresses, and personality in making a determination of whether or nor treatment services were warranted.

The Indian, Latino, and as yet unpublished Black plan for alcohol and drug problems attempt to point up the significance of cultural characteristics or forces bearing on these cultures that make substance abuse in general, and certain types of substance abuse in particular, more probable among their people as compared to the majority (11, pp. 8-15). The Latino statement, for example, implicates the need for a "sense of machismo" as an antecedent to alcohol and other drug problems among Latino males (32, pp. 10-14).

The influence of family background in predicting problems with substance use, perceived evidences of psychopathology, and other possible causal or actuarial factors ought to be considered in making an evaluation of substance problems, and evidence that these factors were considered would assist the Program Office in assessing a program. 
Many authors have cited the influence of family climate as associating with substance abuse in later life. McCelland, for example, characterizes fathers of eventual problems drinkers as more likely to employ "escapist reactions to crisis..." and to be "rejecting, punitive, and nonaffectionate" (31, p. 296). Blaine implicated their mothers as "either emotionally depriving or at the other extreme, over-indulgent" (5, p. 81). With regard to background of abusers of other substances, Johnston found histories of an absence of "adequate parental figures" and parents having "a variety of narcotic traits" in the background of female narcotic abusers (24, pp. 230-236). While these authors don't indicate the extent of these factors in the backgrounds of nonsubstance abusers, the information has value in treatment planning or determining what a person may need in treatment, such as choice of counselor.

The underpinning of the practice of operating substance abuse programs through mental health authorities has been the contention that these problems are psychogenic at least in part. Again, many authors draw. a connection between psychopathology and substance abuse (29, Pp. 97-98; 17, P. 79; 12, P. 69;9, PP. 63-95; 56, P. 120;

15, p. 72; 51, p. 144).

\section{Client Strengths and Resources}

In addition to assessment of problems, consideration of a client's strengths, resources, etc., is a part of the initial assessment. While problems may indicate what eventual goals are desirable for a client to reach, client's strengths, and resources (as well as program and community resources), indicate what objectives and goals are possible to attain. 
There is probably no need for summary reports regarding client resources beyond information like education, employment, etc. However, the extent to which client strengths and resources were considered would be a target of site evaluations to assess the appropriateness of the goals and objectives developed for clients, and the subsequent treatments decided upon. Individual client records ought to include clinicallyoriented information regarding client resources, as they relate to specific goals.

Hollis points out the importance of "ego qualities" as they relate to a person's ability to respond to treatment (21, p. 265). The client's attitude, history of goal-directed behavior, intelligence, reality orientation, ability to delay gratification, and many other factors, have a bearing on ability to overcome substance dependencies and ancilliary problems. Minimum data in client records should include their level of desire to make changes in general or in specific problem areas, estimation of their willingness to apply themselves to making those changes, and factors such as their accuracy of judgement about their ability to make changes. Factors outside of the control of the client, such as family illnesses or the death of a spouse, can be important as well. When these are adverse, their implications for client prognosis or the attainment of goals should be indicated.

The Program office would not look to the evaluation system to directly demonstrate the interrelatedness of mental and emotional disorders with substance abuse or client resources with eventual outcome, without considerable substantiating research. However, it would want to confirm consideration of these factors at the program 
level for the purpose of their assessment of need for intervention and the types of interventions necessary to help the client.

ORGANIZATION OF CLIENT ASSESSMENT INFORMATION IN A FORMAT USEFUL TO THE PROGRAM OFFICE (OR OTHER DECISION MAKERS)

The on-site record review activity is to provide the means of more closely scrutinizing a program with regard to its compliance with legislation and administrative rules. It should therefore, in part, be a means of determining the extent to which a program assessed the relationship of these various client characteristics to substance. problems, and consequent needs for service.

In actual practice, finding information in records and making judgements of the extent to which a program made these assessments is greatly hampered by the present lack of a consistent format of recording among programs and the frequent absence of clear statements of client problems and service needs, in assessment records or ongoing records.

The need to verify program admission decisions would be addressed if standard formats were used that consisted of descriptions of these various client characteristics and problems in objective terms. While the inclusion in a uniform or systematic format of information pertinent to client problem assessment would facilitate some of the audit functions conducted at Program Office site evaluations of service programs, it could, in summary form, increase knowledge and understanding of these problems. Except for inferences from demographic information, our knowledge of the dynamics of substance abuse problems, and those characteristics of clients that are more underlying in nature is almost entirely anecdotal. 
The present capacity to make judgements or determine the needs of clients being admitted to programs without actually going to programs and reviewing records, is based on the Mental Health Information System (MHIS) of summary reports. This is based on admission and termination summaries (CL-1) completed at the program level, and containing demographic information, a basic classification of problems for each client, and eventually an estimation of change in the degree of problems.

With the present MHIS information system the Program office can, for example, make a few low confidence inferences about the range and interrelatedness of client problems based on demographics such as age, sex, income level, marital status, etc. (While some other information is available in the MHIS, it is unreliably filled out by alcohol and drug programs, and therefore judgements based on it are highly suspect.) For example, MHIS data for the alcohol programs reporting in FY 1975-76 indicates that 61 percent of the alcohol residential care facility admissions earn less than $\$ 3,000$ per year. (this is the mean proportion below $\$ 3,000$ per year of those residential care facilities reporting in the Annual Report for Alcohol Programs (3, pp. 1.14, 2a.14, 2b.14, 3.14)). This is one indication to the Program office that these programs might need to make greater efforts at vocational rehabilitation of clients, or income supplementation. Beyond this level of inference, the MHIS does not provide adequate information. A determination of the number of residential facility clients needing psychiatric outpatient care for example, can only be broadly guessed based on MHIS information. The ability to make such determinations would depend on staff making objective statements at the case level regarding such needs, with the information forwarded in summary reports that go beyond the present MHIS. 


\section{CHAPTER III}

\section{GOALS OF TREATMENT}

A competent identification of needs and assessment of client resources lays the groundworkfor the establishment of objectives and goals. In discussing these I will take the term "goal" to mean those general states, abilities, etc., that are sought by a client. Objectives are the steps to be accomplished along the way to goals. Shank defines "objective" as "a test used to determine whether or not you are doing what you want..." in regard to attaining goals (55, p. 1).

The objectivity of goal and objective statements is of concern to the Program Office out of regard for sound clinical practice. Both clients and service workers must understand what they're actually working for if they are to attain goals. Professional jargon regarding the direction of rehabilitation is counter-productive to that end, to the extent that it confuses clients, and keeps both the client and the worker from thinking a problem or goal through to a point of mutual understanding.

An objective statement of something one is attempting to do is one that fits the criteria of empirical verifiability; that is, the results or proof can be seen, or objectively ascertained in some other way. As Kiresuk points out, obtaining objective statements of treatment goals "requires changes in the reporting habits of clinicians" (28, p. 450). Shank's example of a meaningless objective, "client can 
control depression" (55, p. 1), does not meet the criteria of being empirically verifiable. Goal and objective statements must be behaviorally based in order for them to convey meaning. His example of "client cries less than two times per week" is one that both the client and worker attempting to help him can verify progress toward. The needs of the Program office to assess goal establishment and goal attainment at a program level can only be accomplished to the extent an evaluation system elicits such objective, behaviorally-based statements.

Because of the nature of alcohol and drug problems, many workers within the field tend to think in terms of fixed "all or nothing" levels of goal or objective attainment (i.e., the person is either entirely abstinent of the drug which has caused problems in the past, or is making no progress whatsoever). For the addicted abuser, our present level of knowledge and ability to manage substance abuse would lend some credence to this approach. There are a number of reasons, however, why this may not be practical in a great many cases. For one thing, many clients, even though addicted, do not opt for abstinence as a goal early in treatment. Pressure to gain agreement over such a goal can result in a client's termination from treatment, and lost opportunities for addressing their problem when they might be more cognizant of the need for such a goal later on. It is also true that while a person suffering from episodic substance use to levels of physical addiction may be better off to abstain entirely and forever, reduction of frequency from once per month to once per year is a step in the right direction, even if the more desirable goal isn't attained.

Since. people don't attain goals overnight and are seldom 100 percent 
successful in reaching all their stated goals, an evaluation system must provide for measurement of success over time and in increments or degrees of attainment. In his discussion of goal-oriented record-keeping systems, Hardison protrays a system making the attainment of such goals measurable in differing levels. Each goal selected by a client would be listed, and steps or levels of attainment of objectives toward the goals would be described in a scale. A statement of client functioning at the time of entry to treatment would serve as a base for subsequent measurement. Increments of improvement over that level of functioning would be described up to the level perceived to indicate "treatment success or graduation to the next phase of treatment" (18, p. 3). The levels of attainment of goals by virtue of the steps reached would be assessed at follow-up points during the service episode.

The utility of a system like this is the possibility of a continuous feedback loop for viewing progress, according to Kiresuk, the developer of goal attainment scaling (27, p. 221). Direct observation of a client's behavior in group, or some other mode of treatment or client self-reports, and confirmation by family members or other collateral sources can be noted with the levels of attainment achieved over time (18, p. 6).

To the extent a system such as this facilitated concise and objective statements of goals and objectives for individual clients, the Program Office's on-site evaluations of programs would be much more substantive than at present.

The ongoing monitoring of programs, regarding what in general a given program or type of program was attempting to accomplish for its clientele would be enhanced if summary reports (those reports like the present MHIS, that summarize client problems, characteristics, etc., 
at admission and termination) included goal statements. From a Program office standpoint, it would be extremely helpful if an evaluation system provided summary information regarding a range of the broad goals different programs were attempting to help clients attain. To give an exaggerated illustration, we would want to make inquiries if it were reported that an emergency detoxification facility was attempting to assist a significant proportion of its clients to attain controlled social drinking. during their three to five day stay. Since the mission of such a facility is to provide sub-acute care to persons withdrawing from alcohol, their clients would be assumed to be suffering from alcohol addiction. While treatment designed to enable a non-addicted problem drinker to attain social drinking is appropriate in other milieus, it is highly inappropriate (with our present level of technical ability) in a detoxification facility, both because of the target population and because of the long-term nature of this kind of treatment and the follow-up required.

Summary statements of goals could be along lines that included, as appropriate to individual cases, improvements sought in regard to substance use such as abstinence or controlled drinking, coping skills within the family or in single life, interpersonal relations, community life (living in accord or coping with laws, institutions, etc.), and employment, education, health, financial stability, etc.

This information would assist the Program Office to assess not only the goals specific to substance abuse that a program was attempting to assist clients to reach, but also those crossing over into the domain of other programs and even other state level Divisions. Reporting on the establishment of goals that would normally require the resources of other 
programs would assist the Program Office in more closely identifying the need for linkages and coordination in the substance abuse treatment network. The various types of alcohol and drug treatment programs discussed in Chapter I might be thought of as the best guess regarding the range of services necessary to take a person from the level of severely harmful use on through full recovery and independence, or to involve people with different levels of problems or need for services at different levels in the system. At our present level or coordination, these service elements generally operate as individual agencies in a community. To the extent some of the goals of one type of program working with a given group of clients frequently fall into the scope of another, there would be indication of a need for closer cooperation, joint programs, or perhaps even merge under a single clinical manager or delivery system.

Those goals which fit the scope of other Divisions might provide information for the planning of linkages or joint programs between the various state level Divisions such as Welfare, Employment, Corrections, or even Motor Vehicles. There is a tendency for bureaucrats, law makers, and even line staff to think in terms of which Division "owns" various human problems (i.e., the unemployed here, the drug abuser there, etc.). Since no one can grasp the full range of human needs, some division of duties and specialization is of course necessary, The demonstration, however, that reservation residents with alcohol problems nearly always selected goals for obtaining meaningful employment in addition to overcoming their alcohol problems would be a significant step in the direction of establishing justification for program links, or joint programs. 


\section{CHAPTER IV}

\section{ASSESSMENT OF THE RESOURCES APPLIED TO ATTAIN GOALS}

The decisions a program makes about the activities and resources necessary to reach a goal, and their actual application or delivery, are extremely difficult for the Program office to assess. At site evaluations, using the current record system available (or lack of one) for review often tells little more than disposition of a client to different types of treatment. The Program office or other evaluator might encounter a statement after a problem list such as client referred to "therapy", with no indication of what the intent was or in fact whether the client went or for how many sessions, with whom, or what activities "therapy" consisted of. Evaluators could more confidently assess the quality of programs if the resources applied to reaching client goals and objectives were described in very broad terms in summary reports, and then in more specific terms in the progress notes covering the types of treatment delivered, such as individual therapy, group counseling, follow-up visits, medical exams for the patient, etc. Notation of the actual amounts and frequency of such services over time, along with the identity of the service provider, would enable us to make assessments of service provision, and would enable more incisive technical assistance to programs being evaluated, and some ability to generalize that information for the assistance of other programs attempting to meet similar client goals.

This type of information, and the capacity for incisive and critical evaluations of programs that it would provide us, would enable us to 
facilitate the development of greater flexibility, and comprehensiveness of program services. There is a tendency on the part of programs (to be fair it should be stated that this tendency is common to all organizations) to persevere in activities that are familiar or which have historically tended to appear more frequently successful. The assignment by a group therapy-oriented service worker of all clients to groups is an example of this phenomenon. A frequent issue that arises in site evaluations is the lack of individualized treatment in programs for clients, as is required in administrative rules for each service element. In instances where little thought is given to individual needs for various treatments, client satisfaction and resistance can become major obstacles to attainment of treatment goals. In some cases, assignment to treatment with inadequate thought as to its potential impact can be directly harmful to clients. An example would be the assignment of the clinically depressed individual to a highly confrontive mode of group therapy. Information regarding the specific treatment applied to the attainment of goals for clients would enable site visit detection of this kind of misapplication of treatment.

The listing of the actual activities undertaken to assist clients to attain goals would also assist the Program Office to determine the need for linkages to other programs. While we might praise the enthusiasm of a staff member trained in psychiatric nursing, for example, who was providing 50 percent of his or her clients with classes in job search techniques in order to attain occupationally-related goals, that information might lead us to advise involvement of a DVR counselor, or other such specialist, who might provide a better service in that area, and save staff expertise for more appropriate activities. (We might at the 
same time discover that psychiatric nurses were exceptionally wellequipped to provide classes in job search techniques for one reason or another.) 
CHAPTER V

\section{ASSESSMENT OF THE OUTCOME OF TREATMENT}

The Program Office needs information regarding treatment outcome, or its impact on a client's life over time. This is lacking to an embarrassing extent. Aside from our own desire to assess the value of programs, the Legislature requires more and more answers to their question "Does it work?", in each biennial consideration of state-funded programs in general and each Emergency Board consideration of specific programs.

Program outcome measures are required by the Program Office to make several kinds of judgements. The first of course is the determination of the overall utility of entire programs, or treatment techniques. Answers to these questions would of course play a part in decisions about termination, reduction, or expansion of some programs or techniques.

Beyond that, however, are questions that relate to policy issues. As discussed in Chapter I, for example, several service elements have missions pertaining to the maintenance of substance abusers by provision of emergency care, and social services. This stems in part from the valuing of human life and dignity despite the manifestation of problems, or behavior irritating to most of us. The expectation to. provide rehabilitative services, which is another of their missions, stems from the belief that everyone deserves a chance to change, and the practical observation that it is better to deal well with a person's problems once or twice than halfway many times. 
A review of the CL-1 based Annual Alcohol Program Report (3) shows that readmission rates of some detoxification facilities are twice that of others. A comparison of client characteristics reveals significant differences in the characteristics of the treatment populations at the different centers. The facility with the highest readmission rate has only five percent married clients compared with 33 percent at the center with the lowest rate. Forty percent and 17 percent of the two populations are dependent. Seven percent of the clients of the center with the highest readmission rate are women, compared to 18.5 percent for that with the lowest rate. A possible conclusion is that to the extent a facility serves a population that resides in a male ghetto is more disadvantaged, as measured by dependency, and is more estranged from longterm heterosexual relationships (as measured by "married"), the more the facility becomes a "revolving door" (53, pp. 6-8).

While final decisions are not appropriate at this time, because of a lack of process information concerning the actual delivery of rehabilitation services to the more disadvantaged group, such information, and more sensitive outcome indicators may call for a de-emphasis of rehabilitation efforts with this population, and a shift of resources to better maintain services that would be provided regardless of clients' continued substance use and adherence to a treatment plan.

other outcome indicators might, for example, point to a need to abandon the federal policy of volunteerism in treatment of the public inebriate (52, p. 1) in favor of a more coersive approach. This type of decision might be possible if outcome indicators were available on the voluntary detoxification client (whose average stay is two days in some facilities) and could be compared to the involuntary or "Civil Hold" 
client who the police have authority to "commit" to detoxification for 96 hours after demonstrating assaultive behavior, or potential harm to themselves.

To the extent that outcomes for given client groups were comparable across programs, judgements could be made regarding which types of programs worked best, or which combinations of techniques seemed to work best in a given setting.

The following is not intended as a comprehensive listing of those measurement devices, assessment tools, or research techniques which can be applied to alcohol and drug treatment programs in Oregon forthwith. Such devices do not now exist, and can only be developed in formal design as greater knowledge of substance abuse problems and their sequele with which programs deal, are obtained through better record systems, summary reports, and research.

Most systems for the development of outcome information have been designed for use in general mental health/adjustment applications, or with functional disorders such as psychosis, and depression. Some of these devices do, however, have potential application to alcohol and drug evaluation. Since alcohol and drug problems "act" like general mental health problems to the extent they affect job performance, family relations, etc., some of those developed specifically for measuring outcome of mental health programs may have applicable elements.

\section{READMISSION RATES}

Readmission rates of different programs within the same service categories can be of some use in assessing outcome under special circumstances. The review of MHIS-reported rates for detoxification 
programs cited earlier pointed up this utility of using such rates as a hint of different outcomes with demographically different groups. Comparisons of rates between programs with similar clientele might occassionally serve as an indicator of differential outcome due to program features or operation.

Even if CL-1's which make up the MHIS were complete, they would not give adequate information beyond this level. As a matter of fact, the Division has agreed with the Task Force on Alcohol and Drug Program Evaluation to acknowledge that alcohol and drug programs should delete certain elements of the CL-1 which aren't appropriate to alcohol programs.

\section{RECIDIVISM RATES}

Recidivism rates for offenses which result in significant numbers of referrals to programs might have the same type of utility as well. DUII arrests initiate 46 percent of the referrals to outpatient alcohol programs (based on comparisons of first admissions to the state-operated DUII treatment programs to all other outpatient alcohol programs reporting in the Annual Alcohol Programs Report (3)). Recidivism rates have differentiated between, control and treated groups and modes of treatment within these programs for a rough indication of outcome (25, p. 113; 26, p. 108). Two things recommend review of recidivism of at least DUII offenders when assessing outcomes of court-mandated treatment programs: the Motor Vehicles Division will supply recidivism reports on any client (this does not constitute a breach of confidentiality as clients are each referred either by the court as part of sentencing, which is public, recrod, or by the Motor Vehicles Division itself for a restricted drivers 
license recommendation). Even though recidivism rates alone may not be a comprehensive means of evaluating a program, the Legislature always asks what recidivism rates are.

While readmission rates and arrest recidivism may provide some indicators of outcome under certain circumstances, used alone they are unrefined to the extent they might have substantial errors in the interpretations based on them. A program might have low readmission rates, for example, not because it rendered clients free of their problems, but because its staff, methods of treatment, etc., so antagonized clients that they would not return no matter how seriously their problems recurred.

Recidivism rates do not measure those instances of regression to severe substance use, unless the client has the misfortune to also be arrested again. Also, some persons may return to problematic use, but altered in pattern or manifestation such that they are never again noticed by law enforcement personnel. They may similarly be noticed after relatively little abuse. More sensitive outcome indicators are needed to show the impact of services.

\section{GOAL ATTAINMENT SCALING}

Goal Attainment Scaling, developed by Kiresuk, is applicable to treatment planning as mentioned above. For those measurements of outcome which might satisfactorily be done by the program providing treatment, during service episodes or in periods of follow-up after treatment, this might be a useful device. Its outstanding feature is that it is flexible and can be used in a variety of modalities (57, p. 145). It is equivalent to continually reviewing relevance of treatment to a target group of the program being evaluated (19, p. 14). Kiresuk, himself, points out that 
while it may not lend itself to direct comparisons between programs, local standards can be developed and shared between comparable settings (27, p. 227). While comparisons between residential and outpatient programs, or similar programs dealing with different populations, could not be made, some comparisons would be possible between similar programs with similar client groups.

Some type of systematic reporting of goal attainment would enable the Program Office to provide some feedback to the Legislature regarding impact of different programs. It might also provide the means of discriminating very effective versus very ineffective programs.

While in the day to day realities of clinical practice goals are relative, there are cases in which the attainment of fixed or standard goals is desirable. Two basic rationales call for attention to fixed goals. The first is that some clients may require attainment of a given goal in order even to function with minimal independence, health, or we11being. Abstinence, in the case of long-term alcohol or heroin addicts, is an example. The second reason is that many programs are funded with a fixed goal in mind.

Even bearing these requirements in mind does not forbid the use of a more flexible system of measuring outcome via goal attainment. Combinations can be used in which the standard scales are merely part of an overall, individualized format (19, p. 14). Goal attainment indicators of outcome could be assessed either by a particular program, or an outside group of evaluators, such as the Division's Management Support Services Section.

Some outcome considerations require a systematic assessment of a wide range of consequences of the service provided. Goal attainment scaling 
alone cannot be relied on to provide this (19, p. 14). Several types of tools might provide outcome measures of alcohol and drug programs of this type however. There are other tools, or simply sources of information which may have some applicability to the measurement of outcome of specific programs; and may be followed either by programs or someone else.

\section{LIFE ACTIVITIES INVENTORY}

With regards to the impact on clients of programs to treat DUII offenders, and perhaps with some eventual application to other alcohol and drug programs, the Life Activities Inventory (1) may be useful. U. S. Department of Transportation financed studies have shown that "life change" as measured through questionnaires covering alcohol use, income, employment, social activity, family marita] status, and physical health factors are useful in assessing the effectiveness of their rehabilitation programs (2, pp. 1 and 66). Since these programs are based on the experiences of the DUII treatment programs in Oregon

and eight other states during the period they were federally-funded (1970-73) the scales may be useful in Oregon programs. One of the chief drawbacks of this device is the amount of staff time required to administer it. It is given pre-treatment, and at six month intervals afterward, as long as a program chooses to follow a client. Each administration requires about 50 minutes of mechanical questionning.

Several devices which have been used in psychiatric hospitals and community mental health outpatient settings might have some applicability to certain alcohol and drug programs. 
PERSONAL ADJUSTMENT AND ROLE SKILLS (PARS)

A relevant aspect of outcome measurement or follow-up devices like the PARS is that it lends itself to use by a specific program, or by an organization assessing the outcome of several programs. It consists of a 120 item mail-out questionnaire that is completed by a collateral contact or "significant other" identified during the course of treatment. It assesses several dimensions of the client's behavior, including interpersonal involvement, anxiety, agitation, depression, employment, household and outside social skills, and alcohol and drug use. In practice, pre- and post-treatment inquiries generate "change scores" which are used as outcome indicators (57, p. 147).

Beyond the obvious relevance of post-treatment information regarding specific alcohol and drug use, problems in these other areas may be supposed, as pointed out earlier, to be correlates of alcohol and drug problems. That collaterals provide the input on the PARS is a distinct advantage. Collateral contacts would generally provide information in which greater confidence, would be placed as opposed to self-report information. Hargraves views the PARS as a fairly we11-studied device for use as a mail-out (19, p. 17). One possibility with a device such as the PARS is that of randomly selecting cases to be assessed, rather than incurring the expense of applying it to all alcohol and drug clients.

DENVER COMMUNTY MENTAL HEALTH QUESTIONNAIRE (DCMHQ)

The Denver Community Mental Health Questionnaire (DCMHQ) is currently being considered by the Mental Health Division for its applicability to Oregon's alcohol and drug programs. 
This instrument has some attractive features. It is alleged to be useful in application to different treatment modes, with the possibility of comparison between modes $(50, \mathrm{p}, 2)$. Studies comparing the ratings of clients by self-report, versus service worker rating, versus rating by collateral persons indicate high enough levels of agreement to warrant the use of self-reports as the principal outcome measure (50, p. 12).

The DCMHQ consists of scales that indicate psychological distress, involvement with family, involvement with friends, a person's productivity in the vocational realm, their interpersonal aggression, legal difficulties, public system dependency, alcohol/drug abuse and the negative consequences, frequency of hard/soft drug use, and their satisfaction with the services received $(50$, p. 3-6).

From a clinical standpoint, each of these scales would seem to be indicative of success or its lack in overcoming substance abuse and related problems. A disadvantage or constraint of the instrument is that it is administered in an inverview. Program personnel would need to devote time to its use, or outside agency personnel would need to go to a client. In Denver, it was administered in clients' homes, which, while perhaps enhancing their candor, creates greater expense, and does pose infrequent threats to interviewer safety.

\section{COMMUNITY ADAPTATION SCHEDULE (CAS)}

The Community Adaptation Schedule (CAS) consists of self-report measurement of "performance, feelings and beliefs" regarding a client's work, family, social relations, and community functioning. It has the advantage of being a mail-out. Its use as an outcome measure has not been studied, but it is purported to be useful in demonstrating dis- 
abilities in high risk populations, and having the possibility of providing baseline data for longitudinal comparisons of changes in these populations (57, pp. 148-149).

If this, or another device able to do the same thing could be used to show impact of a program on a special population in a defined area, say Indians in Chiloquin, efforts of the Program Office to impact or demonstrate impact on these populations would be greatly enhanced.

\section{GLOBAL ASSESSMENT SCALE}

Something like the Global Assessment Scale might eventually be useful with programs treating the chronic or serious substance abuser whose health is frequently affected. This is based on the Mennringer Health Sickness Rating Scale, and is an improvement over the "improvedunimproved" rating used in clinical and mental health record systems (19, p. 16). As detoxification programs are supplemented by the more comprehensive Incentive Grant programs (now operated in three Oregon communities) for care and follow-up of the public inebriate and other chronic, serious alcohol abusers, such a device might demonstrate program impact on the general physical and mental health of clients.

For methadone maintenance programs and supervised antabuse programs, such a measure might have applicability now, since these programs retain former heroin and alcohol addicts in treatment over periods sufficient to facilitate improvement in the health concerns consequent to the substance abuse and neglect of diet often noted among these clients. A desirable feature of an evaluation system would be the possibility of some uniform system of reporting outcome indicators across all program areas, such as the GAS or DCMHQ. Beyond that, the 
diversity of programs, their target group needs, and the questions which are posed by the Legislature and other funders regarding outcome, all dictate a variety of the kinds of information generated. A capacity to detect different indicators of outcome through application of single studies to some programs, and measures of treatment impact on samples of clients of others will be needed. 


\section{CONSIDERATIONS REGARDING THE IMPLEMENTATION OF AN EVALUATION SYSTEM}

Client rights to confidentiality, program level resistance to an evaluation system, and costs are important considerations.

Unfortunately, there is considerable misunderstanding over confidentiality. This is because of the variety of sources of regulations dealing with the subject. In actual fact, there are relatively few obstacles to evaluation attempts undertaken by persons other than those providing treatment, or evaluation which would require tracking clients after treatment or when progressing from one program element to another.

Administrative Rule 11.020, which governs the inspection of patient records, is a good compilation of the applicable Oregon Statutes. This states that client information may be released "...to persons engaged in scientific research, program evaluation..." at the discretion of the Administrator or a community program director (37, p. 4).

The most recent compilation of interpretations of federal statutes and guidelines (Confidentiality of Alcohol and Drug Abuse Patient Records) states that "...there is a continuous need to discover, test, and evaluate treatment techniques...one should place minimal obstacles in the way of bona fide clinical and epidemiological research." "...disclosures of confidential patient information without consent lemphasis contained in text] for the purpose of scientific research...and program evaluation..." is permitted so long as patient identity is not disclosed in the resultant 
evaluation reports, or information is not used in connection with legal, administrative, or other actions with respect to the client (33, p. 151).

The possibility of tracking a client through the various elements within a system or several different agencies is a "...paramount consideration in the development of adequate evaluation strategies" (4, p. 57).

This is permissable between programs within, or contracted with, the Mental Health Division when information is necessary for their treatment (37, p. 4). Since information from a program, regarding client identity, may be used for evaluation purposes (but not released in subsequent reports) the evaluator would have access to indications that clients received treatment in more than one program. Information regarding outcome of this type of combined treatment could be subsequently released as long as a client was not identified.

Tracking clients between Divisions in the Department of Human Resources for evaluation purposes is not currently permissable in some cases. Department of Vocational Rehabilitation regulations allow release of information regarding services to clients to other Divisions, without consent, but only for the purpose of the treatment or service planning and coordination provided by those Divisions (34, p. 98). The other Divisions have various contrasting regulations, and tracking between Divisions may only be possible after legislative action. Eventual content of the proposed Department of Human Resources consolidation of some of the management functions of the various Divisions may make tracking of clients for evaluation purposes possible.

In my own impression, there will be resistance to an evaluation system on the part of some programs. New operational requirements always incur some ire among programs when "laid on by the Division." Those 
programs which currently do have an interest in evaluation, and the development of the components necessary for evaluation, such as meaningful client records, are in several cases having input to the Division's Task Force on Alcohol and Drug Program Evaluation. There are some notable exceptions, however, and efforts should be made to gain their input.

Because of the rapid growti of alcohol and drug treatment programs since 1973, many have of necessity been preoccupied with the development of service capacity and its provision, at the expense of good client record systems. These programs often state resistance to "spending time writing out goals and objectives and keeping progress notes" when the subject first arises. From experiences in providing technical assistance in site visits, however, it appears that when the utility of a system like GORK to the treatment planning and delivery process is pointed out and illustrated, program personnel become enthusiastic.

Summary reporting of client demographics, problems, goals and objectives and treatment do not immediately simplify and organize the tasks involved in planning and providing treatment. For this reason, some resistance might be expected. Programs do, however, generally acknowledge the prerogative of the Division to require such reports. Most programs have cooperated with the MHIS system of summary reporting, even though it can be seen immediately as providing little information regarding alcohol and drug problems that could provide feedback to programs. To the extent a system of summary reports could be developed which can be completed with little more effort than the CL-1, but had greater face relevance in terms of potential feedback to programs, their resistance would not be a significant obstacle. 
One of the important means of gaining the cooperation of program staff with an evaluation system is training them not only in how to fulfill their role in it, but also what they can get out of it. While this paper has discussed the needs of the Program office for evaluation information, the same information would be extremely valuable to counselors, program managers, etc. These personnel show great interest when information regarding need, or indicators of the impact of various treatment approaches, have been released by the Division.

Considerable training is necessary however so that program personnel can provide and use information through an evaluation system. Oregon substance abuse workers range in sophistication from nationally known clinicians to persons just beginning careers and having little more than enthusiasm. Written material of a fairly technical nature may familiarize some workers with a new evaluation system. For others, fairly concrete explanations will be necessary. A series of workshops covering components of the system might be delivered in each region. Beyond that, actual program site visits can provide more individualized training to mangers and staff. There is a growing tendancy to actually provide technical assistance to programs at such visits. Perhaps staff from the Division's Management Support Services Section (which is doing most of the development of the evaluation system) should be included on site visit teams for this purpose.

Program managers can be assisted in the utilization of evaluation information through the promulgation of planning guidelines. At both the Division and the Program office level guidelines are issued annually for local input to program budget planning, and prioritizations that go into both the alcohol and the drug state plans. 
The cost of an evaluation system may not be significantly greater than that expended now. To the extent a record system eventually saved time in treatment planning, and as opposed to the frequently lengthy narrative descriptions often done by programs now in describing presenting problems, an evaluation system might even save some program components money and resources fairly soon.

The Legislature has been resistant to proposals that evaluation efforts be routinely underwritten as a line item in program budgets. Even through they espouse evaluation, it is unlikely that they will support it with any significant funding increases in the near future. For this reason, the use of the more inexpensive outcome measures such as mail-out questionnaires is probably more practical than routine use of methods such as the life Activities Inventory. At the same time, it might be pointed out that use of an instrument like the DCMHO, which appears to "get into" some problem areas by fairly direct questions, might have applicability to follow-up efforts by treatment personnel since it could structure the interview and provide outcome data at the same time. Follow up appointments, particularly if the client has come to identify with a program or its personnel often times appear to be a point at wich a person will gloss over problem areas nearly as much as at intake--unless some direct questions are asked.

As specific questions arise regarding impact of elements or the success of various treatments on certain kinds of problems, special studies could be conducted by the Division, or directly by programs if they had the resources.

The "bottom line" regarding costs of evaluation is that we really cannot afford not doing it any longer. For the Program office, higher 
administrators, and line staff, an effective evaluation system provides an opportunity of demonstrating good work, and success, as we11 as the threat of the converse. For the citizen, it insures that not only their substance abuse related needs, but also their taxes can be treated appropriately and with respect $(60, \mathrm{p}, \mathrm{xiii})$. 
REFERENCES CITED

1. Anonymous, 1975. Life Activities Inventory, ASAP Short Term Rehabilitation Study, by U. S. Department of Transportation, National Highway Traffic Safety Administration, Washington, D.C.

2. Anonymous, 1976. Program Level Evaluation of ASAP, Diagnosis, Referral and Rehabilitation Efforts, Volume 4--Development - of Short Term Rehabilitation Study, Contract Number DOT-HS-191, U. S. Department of Transportation, National Highway Traffic Safety. Administration, Washington, D.C.

3. Annual Alcohol Program Report, Mental Health Division, Salem, Oregon, 1976.

4. Beigel, Alan, M.D. Evaluation on a Shoestring; A Suggested Methodology for the Evaluation of Communtiy Mental Health Services Without Budgetary and Staffing Support, by University of Arizona College of Medicine, Tuscon, Arizona, (undated).

5. Blaine, Howard T. 1968. The Personality of the Alcoholic, Guises of Dependency, by Harper and Row Publishers, New York, Evanston, and London.

6. Brecher, Edward M., et a1. 1972. Licit and Illicit Drugs, by Little, Brown and Co., Boston, Toronto.

7. Brodsky, Gerry. Quoted from a conversation regarding Drug Abuse Indexes, December 20, 1976.

8. Burbidge, Keith A., et al. 1976. Toward A Substance Abuse Policy for Oregon (Report of the Interim Human Resources Subcommittee. on Alcohol and Other Drug Abuse, 1975-76), by the Legislative Assembly, State of Oregon, Salem, Oregon.

9. Cahalan, Don. 1970. Problem Drinkers, by Jossey-Bass, Inc., Publishers, San Francisco.

10. Cahalan, Don. Some Background Considerations in Estimating State Services Dealing with Alcohol Related Problems, a paper presented at the National Center for Health Statistics for the National Institute on Alcohol. Abuse and Alcoholism, Rockville, Maryland, July 27, 1976.

11. Castro, Stewart L. 1975. 1975 State Plan, the Oregon Indian Commission on Alcohol and Drug Abuse, Salem, Oregon 
12. Chopra, G. S. 1965. "Studies on 300 Indian Drug Addicts with Special Reference to Psycho-Sociological Aspects, Ideology and Treatment," Bulletin on Narcotics, $17(2)$.

13. Committee on Nomenclature and Statistics of the American Psychiatric Association. 1968. DSM-II, Diagnostic and Statistical Manual of Mental Disorders, published by the American Psychiatric Association, Washington, D.C.

14. Cox, Carole and Reginald G. Smart. 1972, "Social and Psychological Aspects of Speed Use; A Study of Types of Speed Users in. Toronto," International Journal of the Addictions, 7 (2).

15. Deleon, George, et a1. "Phoenix House: Changes in Psychopathologícal Signs of Resident Drug Addicts," Archives of General Psychiatry, 28(1), January 1973.

16. Ellsworth, Robert B., et al. "Hospital and Community Adjustment as Perceived by Psychiatric Patients, Their Families, and Staff," The Journal of Consulting and Clinical Psychology Monograph, Volume 32(5), October 1968.

17. Gerard, Donald L. and Conan Cornetsky. 1954. "Social and Psychiatric Study of Adolescent Opiate Addicts," Psychiatric Quarterly, Volume $28(1)$.

18. Hardison, James C. G.O.R.K.: - II (Goal Oriented Record Keeping), printed by Management Support Services, Oregon Mental Health Division, Salem, Oregon, August 1976.

19. Hargraves, William A., et a1. 1975. "Outcome Measurement Instruments for Use in Community Mental Health Program Evaluation," in Resource Materials for Community Mental Health Program Evaluation Part IV, Evaluating the Effectiveness of Services, by the National Institute of Mental Health, Rockvilie, Maryland.

20. Hill, Harris e., et al. 1960. "Personality Characteristics of Narcotic Addicts as Indicated by the MMPI," Journal of General Psychology, Volume 62 .

21. Hollis, Florence. 1972. Casework, A Psychosocial Therapy, by Random House, New York.

22. Joint Commission on Accreditation of Hospitals. 1974. Accreditation Manual for Alcoholism Programs, published by the National Institute on Alcohol Abuse and Alcoholism, Department of Health, Education and Welfare.

23. Joint Commission on Accreditation of Hospita1s. 1975. Standards for Drug Abuse Treatment and Rehabilitation Programs, published by the President's Special Action Office for Drug Abuse Prevention, Washington, D.C., 
24. Johnston, Cecil W. 1968. "A Descriptive Study of 100 Convicted Female Narcotic Residents," Corrective Psychiatry in Journal of Social Therapy, Volume $14 \overline{(4)}$.

25. Kaestner, Noe1. 1976. Collection of Past ASAP Data: Level IV, Analytic Study 6, printed by Oregon Motor Vehicles Division, Salem, Oregon.

26. Kaestner, Noel and William Farr. 1973. Oregon ASAP-Final Report, printed by Alcohol Safety Action Program, Portland, Oregon.

27. Kiresuk, Thomas J. and Sander H. Lund. 1975. "Process and Outcome Measurement Using Goal Attainment Scaling," in Program Evaluation, Alcohol, Drug Abuse, and Mental Health Services, Lexington Books, Lexington, Massachusetts, Toronto, London.

28. Kiresuk, Thomas J. and Robert E. Sherman, "Goal Attainment Scaling: A General Method for Evaluating Comprehensive Community Mental Health Programs," Community Mental Health Journal, Volume 4(6), December 1968.

29. Linn, Lawrence S. "Psychopathology and Experience with Marijuana," British Journal of Addiction (London), Volume 67(1), March 1972.

30. Marden, Parker G. 1973. A Procedure for Estimating the Potential Clientele of Alcoholism Service Programs, prepared for the Division of Special Treatment and Rehabilitation Programs, National Institute on Alcohol Abuse and Alcoholism, Department of Health, Education and Welfare, Rockville, Maryland.

31. McClelland, David C. and William Davis. 1972. The Drinking Man, Alcohol and Human Motivation, The Free Press, New York.

32. McCracken, Maria Elena Bazan. 1976. 1976 State Plan, Oregon Latino Commission on Alcohol and Drug Abuse, Salem, Oregon.

33. Moore, Bettye Ann, et a1. 1976. Confidentiality of Alcohol and Drug Abuse Patient Records, National Drug Abuse Center for Training and Resource Development, Arlington, Virginia.

34. Morton, William Duke. 1974. Privacy, Confidentiality, and Security: A Solution Oriented Approach, Part 2 Appendices, printed by the Program Evaluation and Development Administrative Services Unit, Department of Human Resources, Salem, Oregon.

35. Musolf, Lindon R. David P. Hooper Alcoholic Recovery Center For Project Evaluation, printed by Urban Studies Center, Portland State University, Portland, Oregon, September 1972.

36. Oregon Administrative Rule, Basic Mental Health Services--Draft, Mental Health Division, Salem, Oregon, 1976. 
37. Oregon Administrative Rule 11.020, Patient Records, Mental Health Division, Salem, Oregon, 1974.

38. Oregon Administrative Rule 22.000, Standards for Day Treatment Programs-Draft, Mental Health Division, Salem, Oregon, 1976.

39. Oregon Administrative Rule 52.000, Detoxification Centers, Mental Health Division, Salem, Oregon, 1976.

40. Oregon Administrative Rule 52.005, Alcoholism Residential Care Facilities, Mental Health Division, Salem, Oregon, 1976.

41. Oregon Administrative Rule 53.000, Outpatient Services for Court Mandated Clients, Mental Health Division, Salem, Oregon, 1975.

42. Oregon Administrative Rule 53.010, Drug Evaluation and Treatment Facilities, Mental Health Division, Salem, Oregon, 1975.

43. Oregon Legislative Assembly--1975 Regular Session. 1975. C-Engrossed Senate Bill 1, printed by the Oregon Legislative Assembly, Salem, Oregon. (This document became the Oregon State Motor Vehicles Code July 1, 1976 and will be available under that title in the future.)

44. Oregon Mental Health Division. 1976. 1976-77 State Plan for Alcohol Problems, printed by the Mental Health Division, Salem, Oregon.

45. Oregon Revised Statute 430.306, "Definitions for Alcoholism and Alcohol Treatment Facilities," in Oregon Revised Statutes Relating to Mental Hea1th, Mental Health Division, Salem, Oregon, 1974.

46. Oregon Revised Statute 430.405, "Prevention of Drug Abuse," in Oregon Revised Statutes Relating to Mental Health, Mental Health Division, Salem, Oregon, 1976.

47. Oregon Revised Statute 430.405, "Definitions for Drug Dependent Persons," in Oregon Revised Statutes Relating to Mental Health, Mental Health Division, Salem, Oregon, 1976.

48. Oregon Revised Statute 475.732, "Exemption from Prosecution for Persons Who Voluntarily Apply for Treatment for Drug Use," in Oregon Revised Statutes Relating to Mental Health, Mental Health Division, Salem, Oregon, 1976.

49. Oregon Revised Statute 482.477, "Reinstatement of License of Problem Drinker or Drug Dependent Person," in Oregon Revised Statutes Relating to Mental Health, Mental Health Division, Salem, Oregon, 1976.

50. Reihman, Jacqueline and James A. Ciar10. The Denver Community Mental Health Questionnaire: Development of a Multi-Dimensional Program Evaluation Instrument, by the University of Denver, NIMH Research Grant No. MH20954, Denver, Colorado. 
51. Rosenfeld, Herbert A. 1960. "On Drug Addiction," International Journal of Psychoanalysis, Volume $41(4 / 5)$.

52. Schrimger, Gary. 1976. Guidance Manual for Implementation of the Uniform Alcoholism and Intoxication Treatment Act, Indiana University, Bloomington, Indiana.

53. Schrunk, Mike. "Demographic Factors Associated with Differential Readmission Rates to Detoxification Facilities," Interoffice Memo, Programs for Alcohol and Drug Problems, Mental Health Division, Salem, Oregon, December 1976.

54. Seixas, Frank A. "The Advance of Knowledge About Alcoholism," in National Council on Alcoholism, Inc. News, New York, New York, December 6, 1976.

55. Shank, Steven B. Writing and Scaling Behavioral Objectives-Introductory Workbook Notes, printed by Oregon Mental Health Division, Salem, Oregon, August 1976.

56. Smart, Reginald $G$. and Dianne Feger. 1969. "Illicit LSD Users: Their Social Backgrounds, Drug Use and Psychopathology," Journal of Health and Social Behavior, Volume 10(4).

57. Smith, J.J. 1974. Manual of Principals and Methods for Program Evaluation, printed by King's View Department of Program Information and Evaluation, Reedley, California,

58. Special Action Office for Drug Abuse Prevention. "Drug Treatment Services and Central Intake Units--Federal Funding Criteria," in the Federal Register, Volume 40, Number 102, Part 4, May $27,1975$.

59. Tuchfield, Barry S., et al. Multiple Drug Use Among Persons with Alcohol Related Problems; Patterns of Use and Service Utilization, Research Triangle Institute, Research Triangle Park, North Carolina, September 1975.

60. Zusman, Jack and Cecil Wurster. 1975. Program Evaluation: Alcohol, Drug Abuse, and Mental Health Services, Lexington Books, Lexington, Massachusetts. 